\title{
Molecular cloning and characterization of P5CS gene from Jatropha curcas L.
}

\author{
Guo-Qing Zhuang ${ }^{1}$, Bin $\mathrm{Li}^{2}$, Hong-Ying Guo ${ }^{1}$, Jun-Li Liu' ${ }^{1}$ and Fang Chen ${ }^{3 *}$ \\ ${ }^{1}$ Sichuan Academy of forestry, Chengdu 610081, Sichuan, China. \\ ${ }^{2}$ Nanpin Forestry Bureau, Aba prefecture 623400, China. \\ ${ }^{3}$ Department of Key Lab of Bio-resources and Eco-environment, Ministry of Education, College of Life Science, Sichuan \\ University, Chengdu 610064, China.
}

Accepted 12 September, 2011

\begin{abstract}
$\Delta 1$-Pyrroline-5-carboxylate synthetase, (P5CS) is a bifunctional enzyme (EC 2.7.2.11/1.2.1.41) that catalyses the first two steps of glutamate pathway in proline biosynthesis in plant. The JcP5CS was cloned from the leaves of Jatropha curcas L. The lengthen of the cDNA of JcP5CS was $2675 \mathrm{bp}$, containing a 2148 bp open reading frame, a 117 bp 5'-untranslated region and a 410 bp 3'-untranslated region. The open reading fragment (ORF) encoded a 715 amino acid polypeptide with the molecular weight of $77.54 \mathrm{kDa}$ and the pl value of 6.11. JcP5CS was composed of $\mathrm{N}$-terminal Glutamate-5-kinase (G5K, ProB) and C-terminal glutamic-y-semialdehyde dehydrogenase (GSA-DH, ProA) domains. The conserved Glu-5-kinase, GSA-DH domains, conserved leucine zipper and the putative ATP and NAD(P)H-binding sites was also found. The JcP5CS protein was successfully expressed in Escherichia coli and showed high enzymatic activities. The real-time quantitative PCR results showed that the JcP5CS was induced by drought and salt stress, but not cold stress.
\end{abstract}

Key words: $\Delta 1$-Pyrroline-5-carboxylate synthetase, proline, Jatropha curcas L., expression, molecular cloning, real-time quantitative polymerase chain reaction (RT-PCR).

\section{INTRODUCTION}

Drought and high salinity are the most important environmental factors that cause osmotic stress and impact negatively on plant growth and crop productivity (Boyer, 1982; Chen et al., 2009; Matsui et al., 2008). During osmotic stress, many plants accumulate osmolytes such as proline, glycine, betaine, mannitol and trehalose to maintain a stable intracellular environment (Wang et al., 2007; Zhu, 2002). Proline is one of the most accumulated osmolytes found in plants with salinity and water deficit conditions (Delauney and Verma, 1993; Jime'nez-Bremont et al., 2006; Tripathi et al., 2007; Takano et al., 2009). It has many functions during

${ }^{*}$ Corresponding author. E-mail: qing9501@sina.com.cn. Tel: 8628-8541-7281. Fax: 86-28-8541-7281.

Abbreviations: P5CS, $\triangle$ 1-Pyrroline-5-carboxylate synthetase; PCR, polymerase chain reaction; ORF, open reading fragment; G5K, glutamate-5-kinase; GSA-DH, glutamic- $\gamma-$ semialdehyde dehydrogenase. osmotic stress, osmoprotectant, protein stabilizer, hydroxyl radical scavenger and stabilizer of cell membranes by interacting with phospholipids and carbon and nitrogen reserve after stress relief (Kavi et al., 2005).

In plants, there are two pathways of proline biosynthesis; either from glutamate or ornithine. The glutamate pathway is primarily for proline biosynthesis, especially under osmotic stress conditions (Delauney and Verma, 1993; Hu et al., 1992). There are four steps in the process of proline biosynthesis in plants and the whole process is catalyzed by two enzymes, P5CS and P5CR (Delauney and Verma, 1990; Willett and Burton, 2002). P5CS is a bifunctional enzyme (EC 2.7.2.11/1.2.1.41) that catalyses the first two steps of glutamate pathway in proline biosynthesis in plants. It is a rate-limiting enzyme in the glutamate pathway and exhibits both $\mathrm{\gamma}$-glutamyl kinase and glutamic- $\gamma$-semialdehyde dehydrogenase activities (Delauney and Verma, 1993; Yoshiba et al., 1995). P5CS was cloned from many high plants, for example, Phaseolus vulgaris (Chen et al., 2009), Medicago truncatula (Armengaud et al., 2004), 
Lycopersicon esculentum (Fujita et al., 1998), Arabidopsis thaliana (Strizhov et al., 1997) etc.

Jatropha curcas L. (Euphorbiaceae) is a bush/small tree, which thrives in many areas of the tropics and subtropics in Africa, Asia and America (Keith, 2000). In recent years, there is growing concern about $J$. curcas $L$., because its seed can be used as raw material for biodiesels. In addition to this, it can be used to prevent and/or control erosion, reclaim land and produce feedstuff, soap, cosmetics, pesticides, and anti-cancer and anti-HIV medicines (Dalziel, 1955; Liu et al., 2009; Muanza et al., 1995).

\section{MATERIALS AND METHODS}

\section{Plant materials and stress treatments}

Roots, stems, leaves, flowers, fruits and seeds of $J$. curcas $L$. were collected from Panzhihua City, Sichuan Province and quickly frozen in liquid nitrogen and stored at $-70^{\circ} \mathrm{C}$. Seeds of J. curcas $L$. were germinated in plates filled with soil and irrigated daily with a halfstrength Hoagland solution. J. curcas $L$. grew under $12 \mathrm{~h}$ light/12 h dark condition at $25^{\circ} \mathrm{C}$. 25 days later, the uniform seedlings were transplanted into watertight culture containers filled with halfstrength Hoagland solution. After 5 days, some plants were subjected to drought by adding PEG to the half-strength Hoagland solution until $50 \%(\mathrm{w} / \mathrm{v})$, some were subjected to salt stress by adding $\mathrm{NaCl}$ until $500 \mathrm{mM}$, while the plants were exposed to $4^{\circ} \mathrm{C}$. After stress treatments, leaves were collected and quickly frozen in liquid nitrogen, and stored at $-70^{\circ} \mathrm{C}$.

\section{Isolation of total RNA and synthesizing first strand cDNA}

Total RNA was extracted from young leaves of J. curcas L., with plant RNA isolation reagent (Tiangen Biotech, Beijing, China). Then, the first strand cDNA was sythesized using oligo (dT) 18 (Table 1). The middle fragment primers JCP5CSM-1, JCP5CSM-2 and JCP5CSM-3 (Table 1), were designed based on Ricinus communis P5CS sequence (GenBank accession number: XM 002524184). The nucleotide sequences of the $3^{\prime}$ and $5^{\prime}$ ends of JCP5CS were amplified by the rapid amplification of cDNA ends (RACE) method (Sambrook and Russell, 2001), using three universal primers (oligo $(\mathrm{dT})_{18}, \mathrm{AP}_{1}$, and $\mathrm{AP}_{2}$ ) and four gene specific primers (JCP5CS3'-1, JCP5CS5'-T, JCP5CS5'-1 and JCP5CS5'-2) (Table 1). JCP5CSO-1 and JCP5CSO-2 (Table 1) were used to amplify the ORF of JcP5CS gene. All resulting products were subcloned into pMD18-T vectors (Takara, Dalian, China) and sequenced (Invitrogen, Shanghai, China).

\section{Sequence and phylogenetic analysis}

The sequence homology and the deduced amino acid sequence comparisons were carried out using BLAST at NCBI (http://www.ncbi.nlm.nih.gov/blast). The theoretical isoelectric point (pl) and molecular weight $(\mathrm{Mw})$ of proteins were computed by DNAMAN (version5.2.2). Multiple alignments of amino acid sequences were carried out with the sequence analysis software DNAMAN (version5.2.2) and BLAST (http://blast.ncbi.nlm.nih.gov/ Blast.cgi). Phylogenetic tree was constructed with MEGA program (version4.0) based on amino acid sequences alignment.

\section{Expression of JcP5CS in Escherichia coli}

The coding region of JcP5CS was amplified by PCR with the primer JCP5CS E-1 containing the BamHI site and three protection bases, and the primer JCP5CS E-2 containing the Hindlll site and three protection bases (Table 1). The pMAL-c2E vector and the PCR products were double digested by BamHI and HindlII, after the purification of the digested products by Gel Extraction Mini Kit (Tiangen Biotech, Beijing). Then the ligation was done to obtain the expression plasmids pMAL-JCP5CS. The recombinant plasmid pMAL-JCP5CS and the empty vector pMAL-c2E were transformed into $E$. coli BL21 (DE3). E. coli BL21 (DE3) cells carrying pMAL$J C P 5 C S$ and empty vector pMAL-c2E was grown at $37^{\circ} \mathrm{C}$ and 220 $\mathrm{rpm}$, in LB (Luria-Bertani) media supplemented with $50 \mathrm{~g} / \mathrm{mL}$ kanamycin. Isopropylthiogalactoside was added to cell cultures $\left(\mathrm{OD}_{600}=0.6\right.$ to 0.8$)$ to a final concentration of $1 \mathrm{mmol} / \mathrm{L}$ and grown at $37^{\circ} \mathrm{C}$ for $4 \mathrm{~h}$. The cells of $1 \mathrm{ml}$ culture were harvested by centrifuging at 5,000 rpm for $5 \mathrm{~min}$, dissolved in $100 \mu \mathrm{L} 1 \times \mathrm{SDS}$ sample buffer and boiled at $100^{\circ} \mathrm{C}$ for $10 \mathrm{~min}$. Overexpressed proteins were detected by sodium dodecyl sulfate-polyacrylamide gel electrophoresis (SDS-PAGE).

\section{Determination of JcP5CS activity from transfected cells}

The transformants with plasmid pMAL-JCP5CS were grown at $37^{\circ} \mathrm{C}$ and $220 \mathrm{rpm}$ in LB media supplemented with $50 \mathrm{~g} / \mathrm{ml}$ kanamycin. Isopropylthiogalactoside was added to cell cultures $\left(\mathrm{OD}_{600}=0.6\right.$ to 0.8 ) to a final concentration of $1 \mathrm{mmol} / \mathrm{L}$ and grown at $37^{\circ} \mathrm{C}$ for $4 \mathrm{~h}$. The cells were harvested and washed twice with ice-cold phosphate buffer saline. They were then re-suspended in lysis buffer (50mM Hepes, pH7.5, 10\% glycerol, 1mM EDTA, 1mM EGTA, $1 \mathrm{mM}$ dithiothreitol, and $1 \mathrm{mM}$ phenylmethanesulphonyl fluoride) and sonicated five times for $30 \mathrm{~s}$. The cell lysate was then centrifuged at $12,000 \mathrm{rpm}$ for $10 \mathrm{~min}$ at $4^{\circ} \mathrm{C}$ to remove unbroken cells. Protein concentrations of the supernatant were measured by the Bradford method. P5CS activity was measured according to the method described by Garcia-Rios M. et al. (1997)( Garcia-Rios M. et al.,1997). The P5CS assay was carried out in $100 \mathrm{mM}$ Tris $\mathrm{Cl}$ (pH 7.2), $25 \mathrm{mM} \mathrm{MgCl}, 75 \mathrm{mM}$ Na-glutamate, $5 \mathrm{mM}$ ATP, $0.4 \mathrm{mM}$ NADPH and 10 to $50 \mu \mathrm{g}$ crude proteins at $30^{\circ} \mathrm{C}$ for $20 \mathrm{~min}$. The $\mathrm{NADPH}$ was measured at $340 \mathrm{~nm}$. One unit of the enzyme activity was defined as the decrease in absorption at $340 \mathrm{~nm}$.

\section{Real-time quantitative PCR and free proline determination}

Expression of JCP5CS mRNA was analyzed quantitatively using SYBR Green II real time PCR (Takara, Dalian, China) with Bio-Rad IQ5 detection system according to the manufacturer's instructions. The primer pair (Jc18s1 and Jc18s2) (Table 1) was used to amplify the J. curcas L. $18 \mathrm{~S}$ ribosomal RNA(18SrRNA) (Gene Bank accession no.AY823528) that was used as an internal standard. The P5CS-specic PCR primers was $R q-F$ and $R q-R$ (Table1). The thermocycling program was 40 cycles of $95^{\circ} \mathrm{C}$ for $15 \mathrm{~s}$ and $60^{\circ} \mathrm{C}$ for $1 \mathrm{~min}$ with an initial cycle of $95^{\circ} \mathrm{C}$ for $10 \mathrm{~min}$. After the PCR, a dissociation curve (melting curve) was constructed from the range of 55 to $95^{\circ} \mathrm{C}$ to ensure that primer-dimers and other nonspecific products had been eliminated. Data were collected and processed, including baselines subtraction and threshold definition, with iQ5Cycler software (Biorad, Milano, Italy).

Also, free proline was quantified according to the method of Bates et al. (1973). Fresh leaf material $(0.5 \mathrm{~g})$ was homogenized in $10 \mathrm{ml}$ of $3 \%$ aqueous sulfosalicylic acid and filtered through filter paper. Half milliliter of the filtrate was mixed with $1 \mathrm{ml}$ each of acidninhydrin and glacial acetic acid in a test tube. The mixture was placed in a water bath for $1 \mathrm{~h}$ at $100^{\circ} \mathrm{C}$. The reaction mixture was extracted with $4 \mathrm{ml}$ toluene and the chromophore containing 
Table 1. The primers used in JCP5CS gene clone, prokaryotic expression and Real-time quantitative PCR.

\begin{tabular}{lll}
\hline Primer & Sequence $\left(\mathbf{5}^{\prime} \rightarrow \mathbf{3}^{\prime}\right)$ & Purpose \\
\hline Oligo(dT)18 & GCTGTCAACGATACGCTACGTAACGGCATGACAGTG(T)18 & Adaptor \\
AP1 & GTCAACGATACGCTACGTAACG & Anchor \\
AP2 & TACGTAACGGCATGACAGTG & \\
JcP5CSM-1 & CTTGATGGGAAAGCATGTGC & Middle fragmengt \\
JcP5C M-2 & CCTCGAGCATGAATCCTACTT & primers \\
JcP5CSM-1 & CTTGATGGGAAAGCATGTGC & \\
JcP5CSM-3 & GTGTACAAGAAGTGTTCCATAGC & 3'-RACE primers \\
JcP5C 3'-1 & CCTGTTCTGGGTCATGCTGA & \\
JcP5CS5'-T & CCCTCTTCCCACCCTGGACTTATCACC & 5'-RACE primers \\
JcP5CS5'-1 & GCTTTCCTGGTACTGACCGCATC & \\
JcP5CS5'-2 & AATCACTATCGGTCACAAGGAGC & \\
JcP5CSO-1 & ATGAATGACGGCGTGGATCG & The ORF primers \\
JcP5CSO-2 & TTATGTTACATCCTTGTGGGT & \\
Rq-F & GGGCAAGCAAGGAGATGAAC & \\
Rq-R & TCCAACCTCAGCACCTAAGC & Real-time quantitative PCR \\
Jc18s1 & AGAAACGGCTACCACATC & \\
Jc18s2 & CCAAGGTCCAACTACGAG & \\
JcP5CS E-1 & CGCGGATCCATGAATGACGGCGTGGATCG & \\
JcP5CS E-2 & CCCAAGCTTTTATGTTACATCCTTGTGGGT & expression in E. coli \\
\hline
\end{tabular}

toluene was aspirated, cooled to room temperature, and the absorbance was measured at $520 \mathrm{~nm}$ with a UV visible spectrophotometer. Appropriate proline standards were included for the calculation of proline in the samples.

\section{RESULTS}

\section{Cloning of full length cDNA of JcP5CS}

A $1389 \mathrm{bp}$ fragment was amplified form young leaves of $J$. curcas $L$. by middle fragment primers. The nucleotide sequence showed a high homology with many known P5CS genes, especially the Ricinus communis. The $3^{\prime}$ and $5^{\prime}$ RACE primers were designed based on the fragments. The $3^{\prime}$ and $5^{\prime}$ fragments were amplified by RACE and sequenced. We obtained a 2675 bp long full-length cDNA sequence of P5CS from J. curcas $L$. (GenBank accession no. GU358610) by comparing and aligning the sequences of the $3^{\prime}$ and 5' RACE products.

\section{Sequence and phylogenetic analysis}

The nucleotide sequence of the cDNA was $2675 \mathrm{bp}$, containing a 2148 bp open reading frame, a 117 bp 5'untranslated region and a $410 \mathrm{bp} 3^{\prime}$-untranslated region. The ORF encoded a 715 amino acid polypeptide with the molecular weight of $77.54 \mathrm{kDa}$ and the pl value of 6.11 . The gene was named JcP5CS (J. curcas P5CS). Multiple sequence alignments showed that JCP5CS shared high homology in amino acid sequence, with Ricinus communis P5CS (83.75\%), Phaseolus vulgar P5CS (78.49\%), Arabidopsis thaliana P5CS1 (75.36\%), A. thaliana P5CS2 (76.75\%), Oryza sativa P5CS (73.74\%) and Vigna aconitifolia P5CS (75.80\%). A comparison of the amino acid sequence of JCP5CS with the P5CS of the other plants by BLAST showed JCP5CS was composed of N-terminal Glutamate-5-kinase (G5K, ProB) and Cterminal glutamic- $y$-semialdehyde dehydrogenase (GSADH, ProA) domains. The conserved Glu-5-kinase, GSA$\mathrm{DH}$ domains, conserved leucine zipper and the putative ATP and $\mathrm{NAD}(\mathrm{P}) \mathrm{H}$-binding sites (Figure 1) were also found. The conserved proline feedback inhibition amino acid residue was found in JCP5CS (Phe, at position 129). A Phylogenetic tree of JCP5CS with several plants P5CS was built based on their amino acid sequence by MP (Maximum parsimony) method of cluster analysis using MEGA program, computing 1,000 permutations. Phylogenetic relationships of JCP5CS with several species $P 5 C S$ is shown in Figure 2.

\section{Recombinant protein expression in $E$. coli and JcP5CS activity assay}

After induction with IPTG for $4 \mathrm{~h}$, the clones with recombinant plasmids of pMAL-JCP5CS were harvested. Whole cell lysate, soluble cell extracts and cell pellets were analyzed by $12 \%$ SDS-PAGE. The recombinant protein PMAL-JCP5CS with a molecular weight of about 
PUP5CS MEGAVDPSRSFWIKDVKRVI I KVGTAVVTREEGRLAVGRLGALCEQI KQLNSLEYDI ILVS JCP5CS WUNDGVDRSRAFVKDVKRI VWKVGTAVVTRSDGRLALGRLGALCEQI KELNTQGYDI IVVS AtP5CS2 -WITE I DRSRAFAKDVKRIVVKVGTAVTGKGGRLALGRLGA ICEQLAELNSDGFEVILVS OsP5CS -WASVDPSRSFVRDVKRVI I KVGTAVVSRQDGRLALGRVGALCEQVKELNSLGYEVILVT ATPbinding site

PUP5CS SGAVGIGRORLRFRKL I HSSFADLQKPQLELDGKACAAVGQNSLWALYDT LFT QLDVT SA JCP5CS SGAVG GAQRLRYRRLVNSSFADLQKPQVELDGKACAAVGQNSLWALYDT LFSQLDVT SA AtP5CS2 SGAVGLGAQRLRYRQLVNSSFADLQKPQWELDGKACAGVGQSSLWAYYET WIFDQLDVTVA OSP5CS SGAVGWGAQRLRYRKLVNSSFADLQKPQWELDGKACAAVGQSGLWALYDWLFNQLDVSSS Corserved proline feedback inhibition aming acid residue the

PUP5CS QLLVTDNDFRDKDFRKQLTETVESLLALKI PVIFNENDAVSTRKAPYEDSSGI FWDNDSL JCP5CS OLLVTDSDFRDKDFRKQLNDTVESL INLRVNPI FNENDAVSTRKAPYEDSSGI FMUNDSL AtP5CS2 QWULVDSSARDKDFRKQLSETVKAWULRWRV I PVIFNENDAISTRRAPYKDST GI FW DNDSL OSP5CS QLLVTDSDEENPKFREQLTETVESLLDLKVI PI FNENDA I STRKAPYEDSSGI FWIDNDSL Conserved Leu zipper

PUP5CS SALLALELKADLLVLLSDVEGLYSGPPSDPHSKL I YTYNKEKHQNEI TFGDKSRVGRGGW JCP5CS SALLALELFADLL ILLSDVEGLYSGPPSDPRSKL I HTYVKEKHQGE I TFGDKSRVGRGGW AtP5CS2 AALLSLELKADLLILLSDVEGLYTGPPSDST SKL I HTF I KEKHQDE I TFGEKSKLGRGGW

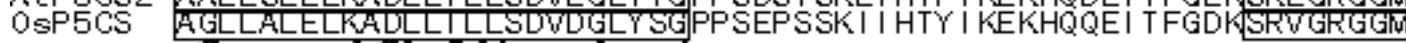
Congrved Glu5-kirag domain

PUP5CS TAKVKAAVHAAEAGTPVITSGFAAENI INVLQGKRIGTLFHKDAHEWAQVIKEVDAREWA JCP5CS TAKVTAAVNAATAGTPVVI T SGYAPEN I TKVLQGERVGTLFHQDAHLWTPFKEVSARKWA ATP5CS2 TAKVKAAVINAAYGGVPVI I T SGYAAEN I SKVLRGLRVGT LFHQDAHLWAPVVDT T SRDWA OSP5CS TAKVKAAVLASINSGTPVI T SGFENRSI LKVLHGEKI GT LFHKNANLIWESSKDVSTREWA

60

60

59

59

PUP5CS VAARECSRRLQALSSEERKQI LLKIADALEANEKI IRI ENEADVTTAQEAGYEKSLVARL JCP5CS VAARESSRRLQALTSQERKKI LLDIADALEANEKL I I I ENEADVDAAQI AGLETSLVARL ATP5CS2 VAARESSRKLQALSSEDRKQI LHDIANALEVNEKT I KAENDLDVAAAQEAGYEESLVARL OSP5CS VAARDCSRHLQNLSSEERKKI LLDVADALEANEDL IRSENEADVAAAGVAGYEKPLVARL

PUP5CS ALKPGKIASLANNWRVIANWDDPI GRVLKRTEI SDGLI LEKTSSPLGVLLIVFESRPDAL JCP5CS ALKPGKI KSLANSIRVLANHEDPI GQVLKRTELADGLLLEKTSSPLGVLL I I FESRPDAL AtP5CS2 V/WHKPGKI SSLAASVRQLAEWEDPI GRVLKKTQVADDL I LEKTSSPI GVLL IVFESRPDAL OSP5CS TI KPGKI ASLAKS IRTLANHEDPINQ I LKKTEVADDLVLEKTSCPLGVLL IVFESRPDAL N AD(P) H birding site

PUP5CS VQIASLAIRSGNGLLLGGGEAKRSNATLHKVITATPDNVGGKLIGLVT SREEI PELLK JCP5CS VQIASLAIRS GNGLLLKGGKEAKRSNEILHKVTTAATPETVGGRLIGLVT SRDEI PDLLK AtP5CS2 VQIASLA I RS GNGLLLKGGKEARRSINATLHKVTIDATPE TVGGLLIGLVT SREEI PDLLK OSP5CS VQIASLAIRSGNGLLLKGGKEAIRSNTILHKVITDAIPRNVGEKLIGLVT TRDEI ADLLK

PUP5CS LDDUIDLVIPRGSNKLVSQIKSSTKI PVLGHADGI CHVWDKSANWEWARRIVLDAKVDY JCP5CS HDDVIDLVIPRGSNALVSQIKASTKI PVLGHADGI CHVYDKSANWIEWAKRI VLDAKVDY ATP5CS2 LDDVI DLVIPRGSNKLVSQIKNSTKI PVLGHADGI CHVWDKSGKLDWAKRI VSDAKLDY OSP5CS LDDVI DLVTPRGSNKLVSQ I KASTKI PVLGHADGI CHVYI DKSADWIDHKL I VWWAKT DY

PUP5CS PAACNAWETLLI HKDL IEKGNLNDI I LALRTEGWLYGGPVASSLLNIPQAHSFHHEYSS JCP5CS PAACNAWETLLVHKDLVHADGFNE I TVELRTEGVNLYGGPRASKEWWLPEAYSFHHEYNS ATP5CS2 PAACNAWETLLVHKDLEQNGFLDDLI YVLQTKGVTLYGGPRASAKLNIPETKSFHHEYSS OSP5CS PAACNAWETLLVHKDLWKSPGLDD ILVALKTEGVNIYGGPIAHKALGFPKAVSFHHEYSS

PUP5CS LACTVEIVDDVYAAI DHINLHGSAHTDSI VAEDNEVANVFLRQVDSAAVIFHNASTRYSDG JCP5CS WUCT I EI VDDW YAI DHI HQHGSAHTDCI I AEDHEVAEVFLHQVDSAAVIFHNASTRF SDG AtP5CS2 KACTVEIVEDVYGAI DHI HQHGSAHTDCIVTEDSEVAE IFLRQVDSAAV/FHNASTRFSDG OSP5CS WACTVEFVDDVQSAI DHI HRYGSAHT DCIVTTDDKVAETFLRRVDSAAVFHNASTRFSDG Conserved GSA-DH damain

PuP5CS ARFGLGAEVG STSRIHARGPVGVEGLLTTRWI LKGTGHWDGDRGWYTHKDLAT--JCP5CS ARFGLGAEVGISTGRIHARGPVGVE GLLTTRWI LRGSGQWVDGDKG I YTHKDVT---AtP5CS2 FRFGLGAEVG STSRTHARGPVGVEGLLTTRWI WRGKGQWDDGNGI WYTHKDLPVLQRT OSP5CS ARFGLGAEVGISTGRTHARGPVGVEGLLTTRWI LRGRGQWNNGLDWVYTHKSLPLQ---

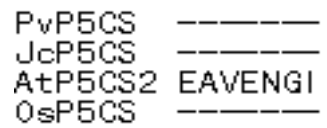

Figure 1. Amino acid sequence alignment of PVP5CS (accession no. ABY61079), JcP5CS (accession no. GU358610), AtP5CS2 (accession no. NP191120) and OsP5CS (accession no. BAA19916). The conserved Gk, GSA-DH domains, putative ATP and $\mathrm{NAD}(\mathrm{P}) \mathrm{H}$-binding sites, conserved leu zipper and the conserved proline feedback inhibition amino acid are boxed.

$119 \mathrm{kD}$ was observed in total protein extracts, soluble cell extracts and cell pellets (Figure 3, lane 4 to 6). The recombinant protein pMAL-JCP5CS molecular weight was higher than the molecular weight of JcP5CS (77.54 kD) because the recombinant protein contained maltosebinding protein $(42.3 \mathrm{kD})$. 


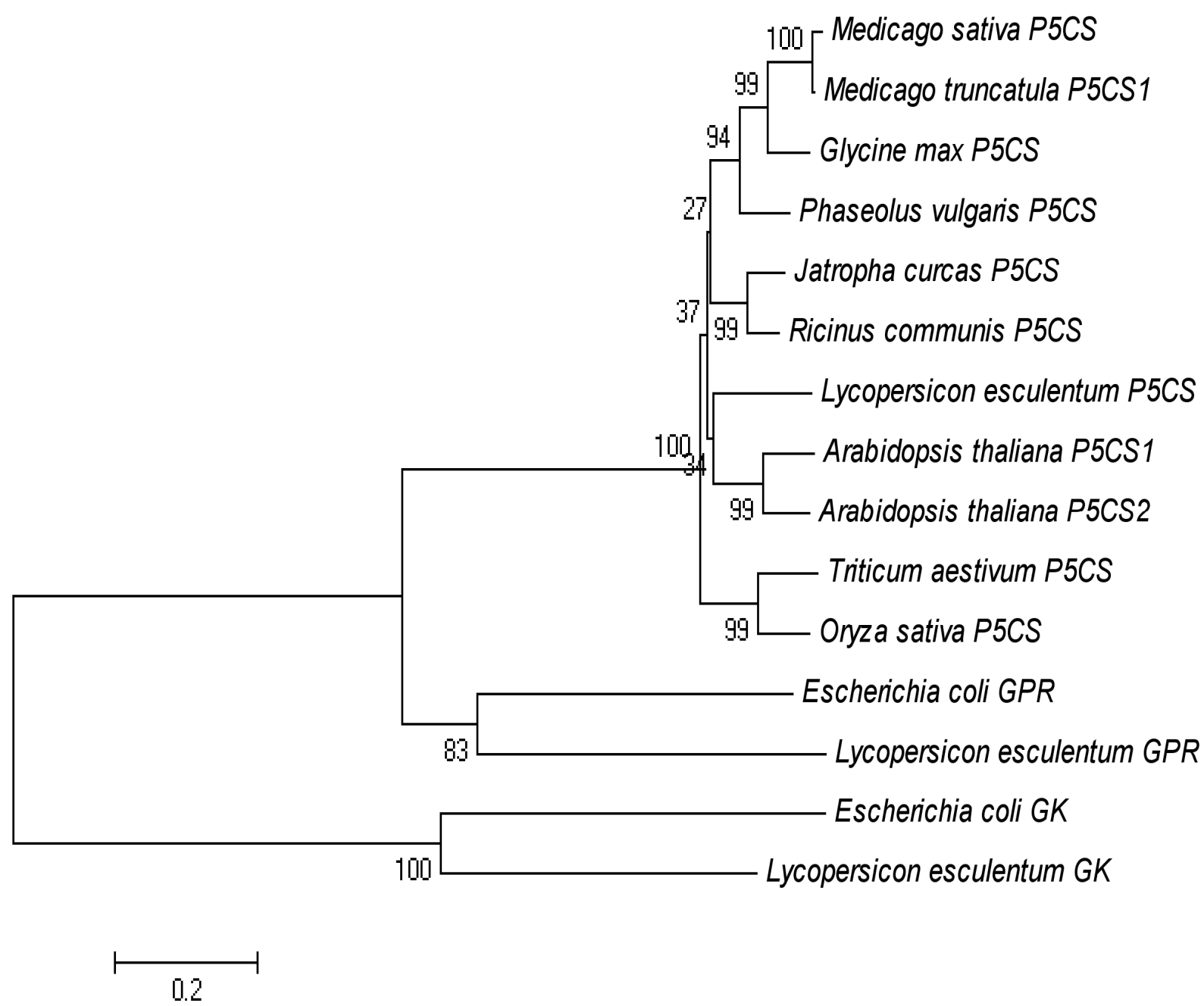

Figure 2. The phylogenetic tree of JCP5CS (J. curcas P5CS) was built from amino acid sequences. GeneBank. accession numbers for these sequences are as follows: Medicago sativa P5CS (CAA67069), Medicago truncatula P5CS (CAC82184), Glycine max P5CS (AAR86688), Phaseolus vulgaris P5CS (ABY61079), Ricinus communis P5CS (XP002524230), Lycopersicon esculentum P5CS (AAB67875), Arabidopsis thaliana P5CS1 (NP181510), Arabidopsis thaliana P5CS2 (NP191120), Triticum aestivum P5CS (AAX35536), Oryza sativa P5CS (BAA19916), Escherichia coli GPR (CAA25364), Lycopersicon esculentum GPR (AAB67877), Escherichia coli GK (CAA25363) and Lycopersicon esculentum GK (AAB67876). The reliability of the tree is measured by bootstrap analysis with 1,000 replicates.

The JcP5CS activity assay was measured as GarciaRios $\mathrm{M}$ described. Protein concentrations of the soluble part were measured by the Bradford method. The soluble part of $E$. coli with recombinant plasmids pMAL-JCP5CS after $4 \mathrm{~h}$ post-induction with $1.0 \mathrm{mM}$ IPTG was set as the control. The JcP5CS activity was $95.87 \mathrm{U} / \mathrm{mg}$.

\section{Expression patterns of JcP5CS in response to drought, salt and cold stresses}

The expression of JCP5CS and proline levels were measured as previously described, in drought, salt and cold stress treated J. curcas leaves at different time points (Figure 4). Drought stress treatment caused rapid introduction of JcP5CS expression up to 6.1 fold at $2 \mathrm{~h}$ after treatment, followed with a reduction to 4 fold at $4 \mathrm{~h}$. Then, JCP5CS expression sharply reduced to 1.2 fold at 6 $\mathrm{h}$, followed by an increase to 1.5 fold at $9 \mathrm{~h}$. It maintained at low level from 12 to $36 \mathrm{~h}$. After that it reduced to 0.24 fold at $48 \mathrm{~h}$. During the drought stress treatment process, proline level increased from 1.0 fold at $2 \mathrm{~h}$ to 4.6 fold at $12 \mathrm{~h}$, followed by a reduction from $24 \mathrm{~h}$ and then an increase to 4.2-fold again at $48 \mathrm{~h}$. Salt stress treatment caused rapid introduction of JCP5CS expression up to 6.5 fold at $2 \mathrm{~h}$ after treatment, followed with a reduction to 2.8 fold at $4 \mathrm{~h}$. Then, JCP5CS expression sharp reduced to1.1 fold at $6 \mathrm{~h}$ and maintained at low level from 9 to 24 $\mathrm{h}$. After that it reduced to 0.12 fold at $36 \mathrm{~h}$ and 0.08 fold at $48 \mathrm{~h}$. During the drought stress treatment process, 


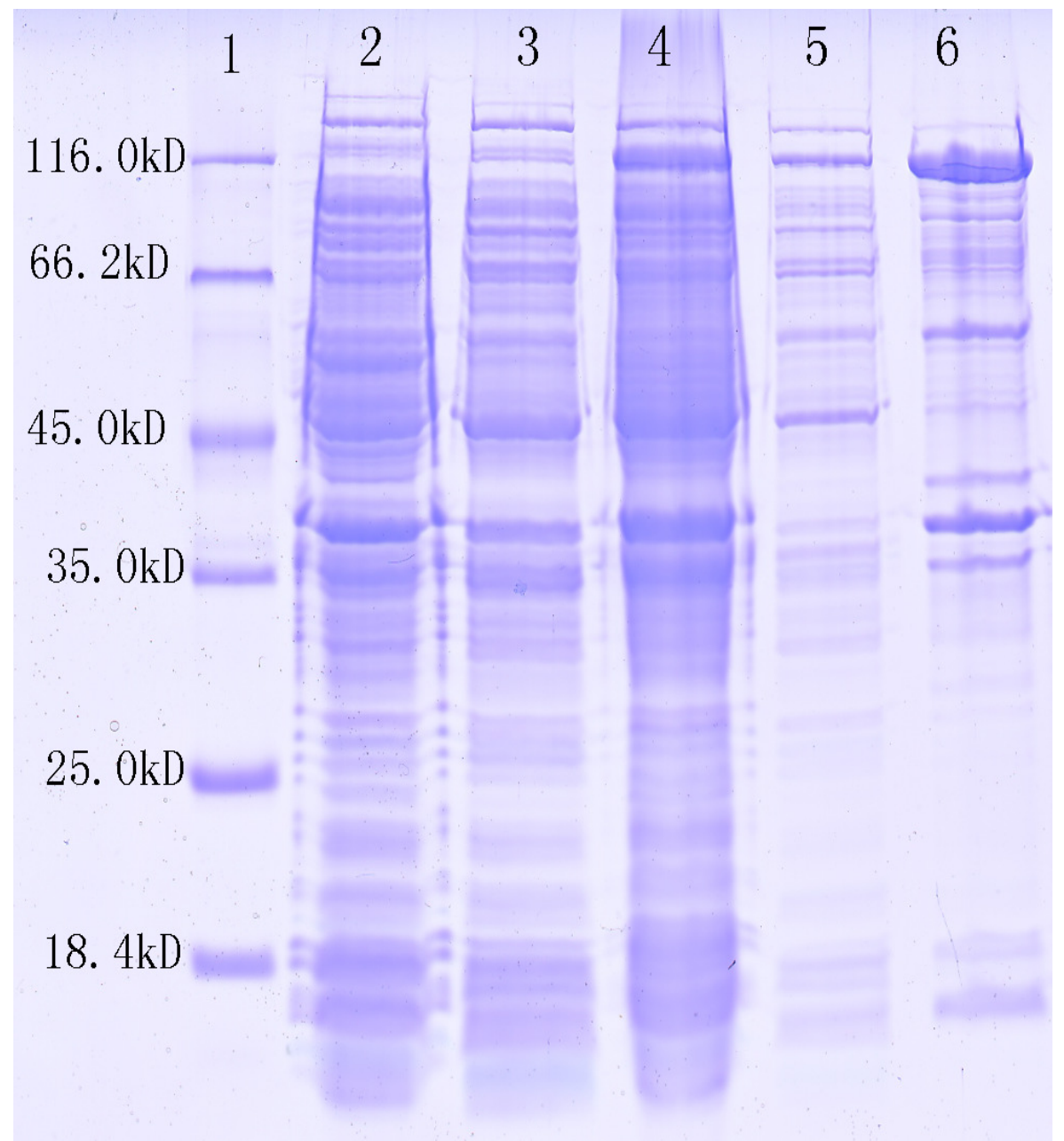

Figure 3. Expression of JCP5CS in Escherichia coli. Lane 1, Protein marker; lane 2, total protein extracts from BL21 E. coli cells containing the empty vector pMAL-c2E after $4 \mathrm{~h}$ post-induction with $1.0 \mathrm{mM}$ IPTG; lane 3, total protein extracts from non-induced BL21 $E$. coli cells containing the plasmid pMAL-JcP5CS; lane 4, total protein extracts from BL21E. coli cells containing the plasmid pMAL-JCP5CS after $4 \mathrm{~h}$ post-induction with $1.0 \mathrm{mM}$ IPTG; lanes 5 and 6 , soluble and pellet part of $E$. coli with recombinant plasmids pMAL-JcP5CS after $4 \mathrm{~h}$ post-induction with $1.0 \mathrm{mM}$ IPTG.

proline steadily accumulated from 1.0 fold at $2 \mathrm{~h}$ to 13.1 fold at $24 \mathrm{~h}$, followed by a reduction from $24 \mathrm{~h}$. More also, cold stress treatment caused introduction of JCP5CS expression up to 1.25 fold at $2 \mathrm{~h}$ after treatment, followed with a rapid reduction to 0.41 fold at $4 \mathrm{~h}$. It maintained a very low level from 4 to $48 \mathrm{~h}$. During the cold stress treatment process, proline steadily accumulated from 0.75 -fold at $2 \mathrm{~h}$ to 6.7 -fold at $24 \mathrm{~h}$, followed by a reduction from $24 \mathrm{~h}$.

\section{DISCUSSION}

In E. coli, conversion of glutamate to $\Delta 1$-pyrroline-5carboxylate is mediated by two enzymes, Y-glutamyl kinase (GK, EC 2.7.2.11) and glutamic- $\gamma$-semialdehyde dehydrogenase (GSA-DH, EC 1.2.1.41). These two enzymes are encoded by proB and proA, respectively (Delauney and Verma, 1993; Deutch et al., 1984). In higher plants the process is mediated by P5CS, which exhibited both GK and GSA-DH activities. VaP5CS ( $V$. aconitifolia P5CS) was the first cloned gene that encoded the P5CS enzyme (Hu et al., 1992). PvP5CS, AtP5CS, OsP5CS and RcP5CS are also encoding a bifunctional enzyme like VaP5CS. However, in tomato, the tomPRO1 locus is unusual, because it contains two open reading frames encoding GK and GSA-DH, respectively, thus resembling prokaryotic polycistronic operons (GarciaRios M. et al.,1997).

We succeeded in cloning the full length P5CS cDNA from J. curcas $L$. by RACE. Multiple sequence alignments showed that JCP5CS shared high homology in amino 


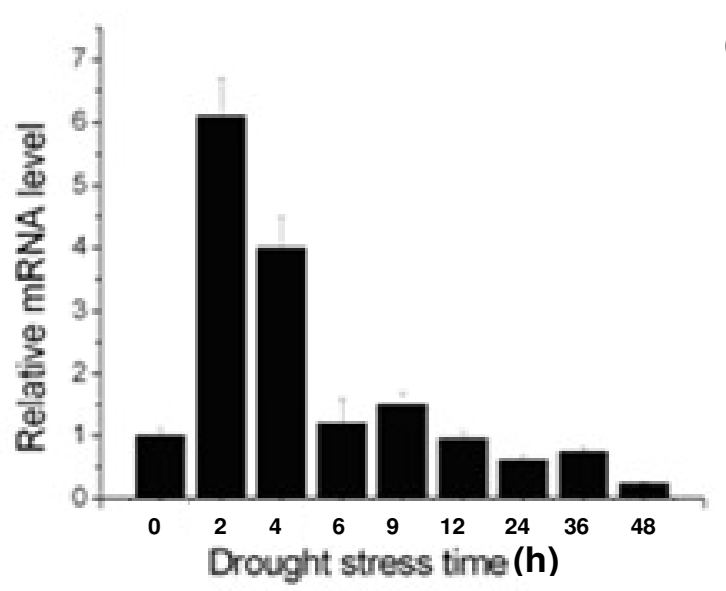

(A)
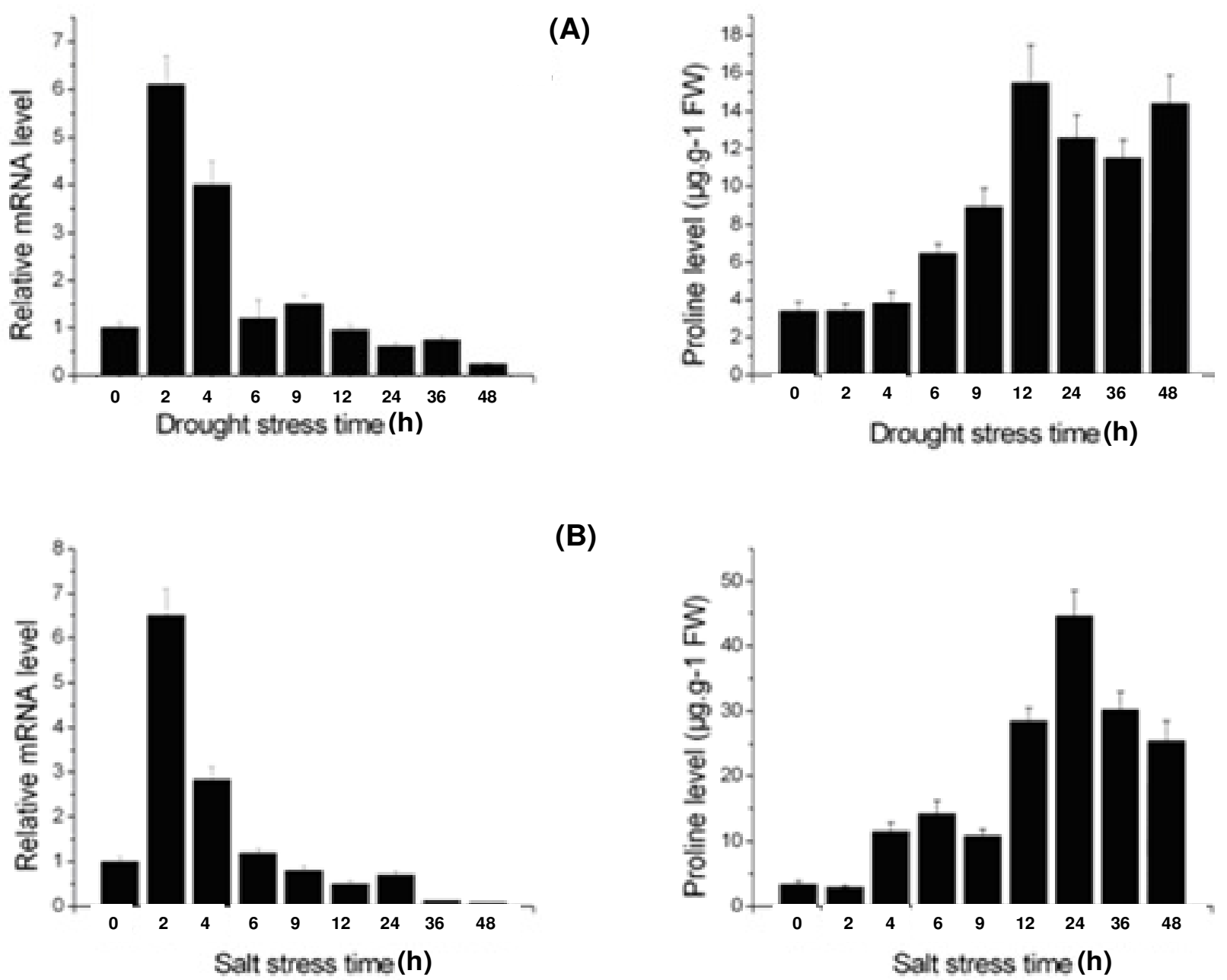

(B)
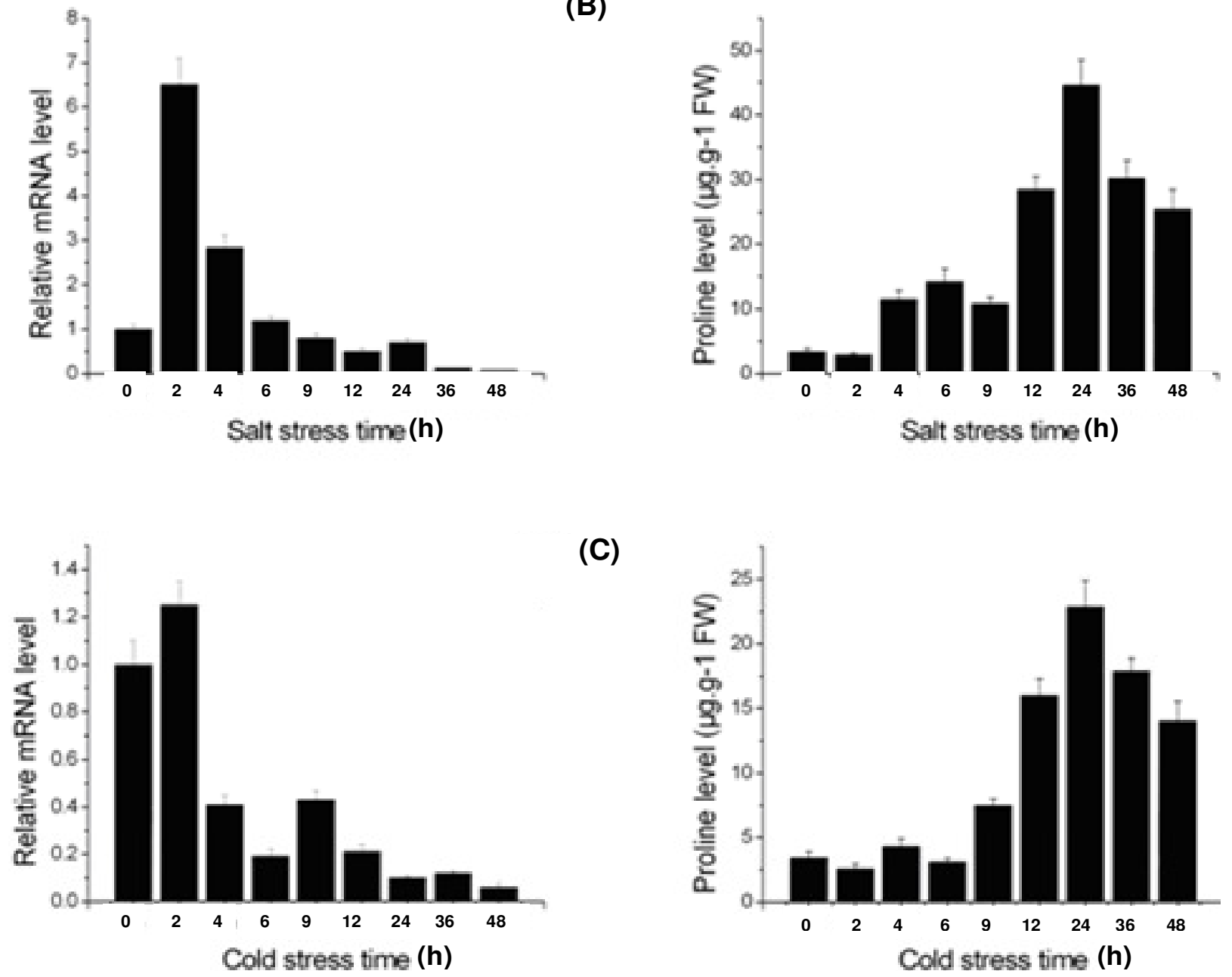

(C)

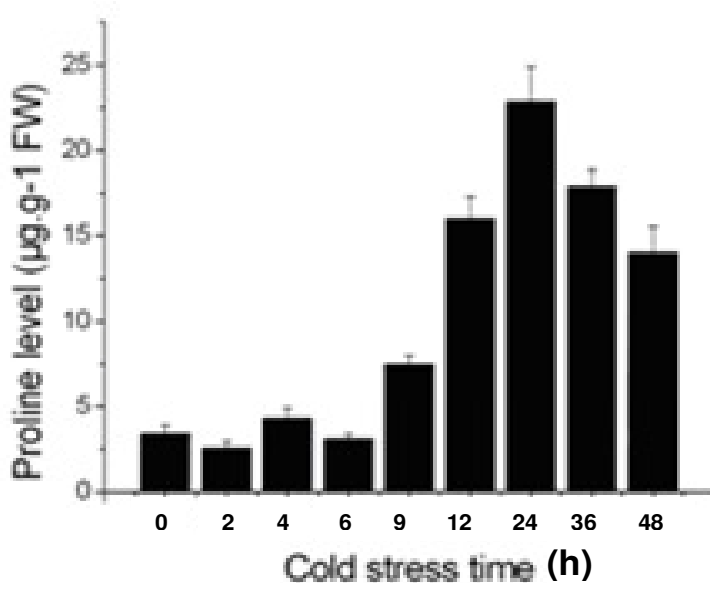

Figure 4. Expression of JCP5CS and proline levels in different stress treatments. (A) Represents drought stress treatments; (B) represents salt stress treatments. (C) represents cold stress treatments. Data are presented as the mean $\pm S D(n=3)$.

acid sequence, with $R$. communis P5CS (83.75\%), $P$. vulgar P5CS (78.49\%), A. thaliana P5CS1 (75.36\%), A. thaliana P5CS2 (76.75\%), O. sativa P5CS (73.74\%) and
V. aconitifolia P5CS (75.80\%). Sequence analysis showed JCP5CS had a complete ORF and encoded a bifunctional enzyme P5CS. As shown in Figure 3, the result 
indicated that the JCP5CS gene could express in E. coli cells. Crude protein extract was used for the enzyme activity assay and results showed that the JCP5CS activity was $95.87 \mathrm{U} / \mathrm{mg}$. It indicated that we obtained the functional P5CS enzyme. In higher plant, tomPRO2 which encode the P5CS in Lycopersicon esculentum, was expressed in $E$. coli cells (Fujita et al., 1998), but this enzyme was not obtained in a soluble form. VaP5CS was expressed and exhibited high level of GK activity (Hu et al., 1992).

There have been many researches about P5CS expression pattern in higher plants. The level of $\mathrm{VaP5CS}$ transcripts in $V$. aconitifolia leaves and root is increased by treatment with $200 \mathrm{mM} \mathrm{NaCl}$ (Hu et al., 1992). The expression of OsP5CS was induced by salt, dehydration, cold and exogenous ABA treatments, but not by heat treatment (Igarashi et al., 1997). PVP5CS expression was increased by the treatment of drought, salt and cold stress (Chen et al., 2009). RT-PCR analysis showed that the transcription of MsP5CS1 and MsP5CS2 were enhanced in roots exposed to $\mathrm{NaCl}$ (Ginzberg et al., 1998). The expression of AtP5CS1 increased by 5 to 6 fold and the AtP5CS2 increased 2 fold in drought stress treatment (Strizhov et al., 1997). The expression of AtP5CS1 also increased in Arabidopsis when subjected to drought, $\mathrm{NaCl}$ and ABA treatments (Yoshiba et al., 1995).

Our results show that JCP5CS is induced by drought and salt stress, but not by cold stress. The JCP5CS expression accumulated at the early time of drought and salt stress treatments, but the proline accumulated at the later time of osmotic stress treatments. Proline biosynthesis is regulated by end-product inhibition of GK in bacteria (Hayzer and Leisinger, 1980). The wild type $E$. coli GK showed $50 \%$ inhibition at $0.2 \mathrm{mM}$ proline, while a mutant form of the enzyme is about 200 fold less sensitive to end-product inhibition. The mutation from aspartic acid to asparagine is responsible for the resistance to endproduct inhibition of GK. The amino acid site is also found in VaP5CS (128, Asp) (Hu et al., 1992).

There is a different opinion that the conserved Phe residue (129) in VaP5CS was involved in feedback inhibition instead of Asp residue (128) (Hong et al., 2000). Sequence analysis showed the JCP5CS both had Asp residue (128) and Phe residue (129). It therefore implies JCP5CS enzyme might be inhibited by proline to regulate the biosynthesis.

In conclusion, we succeeded in obtaining the P5CS from $J$. curcas $L$. and performed osmotic expression analysis and functional analysis. To further understand the function of this gene, more researches based on these primary results are needed.

\section{ACKNOWLEDGEMENTS}

The authors thank Prof. Yong-Jiong Jia, Dr Ying Xu, Dr Lin Tang and Prof. Sheng-Hua Wang for technical assistance. We also thank Wen-Guo Wang, Liang Li and
Pei Hou for helpful comments on the manuscript. This work was supported by a grant from the National Science and Technology Support; J. curcas L. Seed and Seedling Propagation Technology Standardization Research and Demonstration (No. 2007BAD50B02).

\section{REFERENCES}

Armengaud P, Thiery L, Buhot N, March GG, Savoure A (2004). Transcriptional regulation of proline biosynthesis in Medicago truncatula reveals developmental and environmental specific features. Physiol. Plant. 120: 442-450.

Bates LS, Waldren RP, Teare ID (1973). Rapid determination of free proline for water-stress studies. Plant Soil, 39: 205-207.

Boyer JS (1982). Plant Productivity and Environment. Science, 443-444.

Chen JB, Wang SM, Jing RL, Mao XG (2009). Cloning the PvP5CS gene from common bean (Phaseolusvulgaris) and its expression patterns under abiotic stresses. J. Plant Physiol. 166: 12-19.

Dalziel JM (1955). The useful plants of west-tropical Africa. Crown agents for oversea governments and administration, London, p.147.

Delauney AJ, Verma DPS (1990). A soybean gene encoding $\Delta^{1}$ pyrroline-5- carboxylate reductase was isolated by functional complementation in Escherichia coli and is found to be osmoregulated. Mol. Gen. Genet. 221: 229-305.

Delauney AJ, Verma DPS (1993). Proline biosynthesis and osmoregulation in plants. Plant J. 4: 215-223.]

Deutch AH, Rushlow KE, Smith CJ (1984). Analysis of tbe Escherichia coli proBA locus by DNA and protein sequencing. Nucleic Acids Res. 12(15): 6337-6355.

Fujita T, Maggio A, Garcia-Rios M, Bressan RA, Csonka LN (1998). Comparative analysis of the regulation of expression and structures of two evolutionarily diver gentgenes for $\Delta^{1}$-pyrroline- 5-carboxylate synthetase from tomato. Plant Physiol. 118: 661-674.

Garcia-Rios M, Fujita T, Christopher LP, Locy RD, Clithero JM, Bressan RA, Csonka LN (1997). Cloning of a polycistronic cDNA from tomato encoding $\mathrm{Y}$-glutamyl kinase and $\mathrm{Y}$-glutamyl phosphate reductase. Proc. Natl. Acad. Sci. USA.94: 8249-8254.

Ginzberg I, Stein H, Kapulnik Y, Szabados L, Strizhov N, Schell J, Koncz $C$, Zilberstein A (1998). Isolation and characterization of two different cDNAs of $\Delta^{1}$-pyrroline-5-carboxylate synthetase in alfalfa, transcriptionally induced upon salt stress. Plant Mol. Biol. 38: 755C764.

Hayzer DJ, Leisinger THJ (1980). The Gene-Enzyme Relationships of Proline Biosynthesis in Escherichia coli .Gen. Microbiol. 118: 287-293.

Hong Z, Lakkineni K, Zhang Z, Verma DPS (2000). Removal of feedback inhibition of $\Delta^{1}$ - pyrroline-5-carboxylate synthetase results in increased proline accumulation and protection of plants from osmotic stress. Plant Physiol. 122: 1129-1136.

Hu CAA, Delauney AJ, Verma DPS (1992). A bifunctional enzyme $\left(\Delta^{1}\right.$ pyrroline-5- carboxylate synthetase) catalyzes the first two steps in prolie biosynthesis in plants. Proc. Natl. Acad. Sci. USA; 89: 93549358.

Igarashi Y, Yoshika Y, Sanada Y, Yamaguchi-Shinozaki K, Wada K, Shinozaki K (1997). Characterization of the gene for delta- pyrroline-5carboxylate synthetase and correlation between the expression of the gene and salt tolerance in Oryza sativa L. Plant Mol. Biol. 33: 857-865.

Jime'nez-Bremont JF, Becerra-Flora A, Herna'ndez-Lucero E, Rodrı'guez-Kessler M, Acosta Gallegos JA, Ramı'rez-Pimentel JG (2006). Proline accumulation in two bean cultivars under salt stress and the effect of polyamines and ornithine. Biol. Plant. 50: 763-766.

Kavi Kishor PB, Sangam S, Amrutha RN, Sri Laxmi P, Naidu KR, Rao KRSS, Rao S, Reddy KJ, Theriappan P, Sreenivasulu N (2005). Regulation of proline biosynthesis, degradation, uptake and transport in higher plants: its implications in plant growth and abiotic stress tolerance. Curr. Sci. 88: 424-438.

Keith O (2000). A review of Jatropha curcas: an oil plant of unfullled promise. Biomass, Bioenergy, pp. 191-195. 
Liu B, Yao L, Wang WG, Gao JH, Chen F, Wang SH, Xu Y, Tang L, Jia YJ (2009). Molecular cloning and characterization of phospholipase D from Jatropha curcas L.. Mol. Biol. Rep. DOI 10.1007/s11033-0099727-8.

Matsui A, Ishida J, Morosawa T, Mochizuki Y, Kaminuma E, Endo TA Okamoto M, Nambara E, Nakajima M, Kawashima M, Satou M, Kim JM, Kobayashi N, Toyoda T, Shinozaki K, Seki M (2008). Arabidopsis Transcriptome Analysis under Drought, Cold, High-Salinity and ABA Treatment Conditions using a Tiling Array. Plant Cell Physiol. 49(8): 1135-1149.

Muanza DN, Euler KL,Williams L, Newman DJ (1995). Screening of antitumor and anti-HIV activities of nine medicinal plants from Zaire. Int. J. Pharmacogn. 33: 98-106.

Sambrook J, Russell DW (2001). Molecular cloning: a laboratory manual, 3rd edn. ColdSpring Harbor, New York.

Strizhov N, Abraham E, Okresz L, Blichling S, Zilberstein A, Schell J, Koncz C, Szabados L (1997). Differential expression of two P5CS genes controlling proline accumulation during salt stress requires $A B A$ and is regulated by $A B A 1, A B I 1$ and $A X R 2$ in Arabidopsis. Plant J. 12 557-69.

Takano K, Higashi R, Okada J, Mukaiyama A, Tadokoro T, Koga Y, Kanaya S(2009). Proline Effect on the Thermostability and Slow Unfolding of a Hyperthermophilic Protein. J. Biochem. 145(1): 79-85.

Tripathi SB, Gurumurthi K, Panigrahi AK, Shaw BP (2007). Salinity induced changes in proline and betaine contents and synthesis in two aquatic macrophytes differing in salt tolerance. Biol. Plant. 51: 110115.
Wang ZQ, Yuan YZ, Ou JQ, Lin QH, Zhang CF (2007). Glutamine synthetase and glutamate dehydrogenase contribute differentially to proline accumulation in leaves of wheat (Triticum aestivum) seedlings exposed to different salinity. J. Plant Physiol. 164: 695-701.

Willett KS, Burton RS (2002). Proline biosynthesis genes and their regulation under salinity stress in the euryhaline copepod Tigriopus californicus. Comparative Biochem. Physiol. Part B, 132: 739-750.

Yoshiba Y, Kiyosue T, Katagiri T, Ueda H, Mizoguchi T, YamaguvhiShinozaki K, Wada K, Harada Y, Shinozaki K (1995). Correlation between the induction of a gene for $\Delta^{1}$ - pyrroline-5- carboxylate synthetase and the accumulation of prolinein arabidopsis thaliana under osmotic stress. Plant J. 7: 751-760.

Zhu JK (2002). Salt and drought stress signal transductionin plants. Annu. Rev. Plant Biol. 53: 247-273. 